\title{
Complexity vs Simplicity: The Contrasts of Architectural Language in the Past and in the Present
}

\author{
By Patrizia Burlando* \& Sara Grillo ${ }^{\dagger}$
}

The architecture, the landscape, the urban planning, the information technology and the other disciplines merge and move towards extreme evolution. In search of extreme and unusual shapes and heights to overcome a fictitious challenge between power and ability, it is opposed to the need to simplify the representation and make it elementary. The design of the city is an action that humankind has always done and that the various cultures and populations have developed by creating different rules: orthogonal grids, main axes, concentric patterns and the most varied forms. The development of new settlements is determined by the design of new infrastructures, new axes and the creation of new blocks and buildings. A peculiar phenomenon of recent years, which inspires and goes beyond experiences of the past (ideal cities), is represented by the creation of new cities in the United Arab Emirates where the limits do not exist, the territory is designed with artificial forms, the coastline is remodeled with figures and elementary representations, ever higher and bizarre skyscrapers rise with extreme rapidity requiring considerable economic resources and technological capabilities. This search for complex forms of buildings is observed all over the world; it is now a challenge among the greatest architectural firms to use parametric design to create new buildings. This technology allows us to overcome the limits of the past and the design of intrepid shapes that release from simple geometric shapes, creating a new contemporary language. It is clear that without a proper cultural and intellectual background it is only a game with shapes. This new way of designing the city and its parts must be in some way understandable by everyone, therefore the need to find clear and elementary methods of representation. The general agreement and the acceptance of new forms are essential for identification in the new language. Actually, even if the design process is represented in a schematic way, very complex design software is used.

\section{Introduction}

"If it is necessary to know and to write, for the same reason every engineer must get to express himself, that is to draw, more exactly that it is possible."1

\footnotetext{
*Professor, University of Genova, Italy.

${ }^{\dagger}$ Architect, University of Genova, Italy.

1. D. Tessari, La Teoria delle Ombre e del Chiaro-Scuro (Torino: Camilla e Bertolero, 1880), p. 32.
} 
The study intends to analyze the evolution of forms through their representation from the design of the landscape to that of the single object of architecture.

We want to obtain extreme and unconventional shapes and outside the box to win a fictitious challenge between power and capacity, to which the need to simplify the representation and make it elementary is opposed.

The idea of architecture we have today is profoundly different from that of the past, both in terms of formal and functional aspects.

Forms of architecture in the purest and most intrinsic meaning have always existed, it is not the intention of this study to thoroughly investigate the meaning of architecture, but it is inevitable to think of architecture as a search for shelter and protection.

Since prehistoric times man tries to use the shapes of the territory in his favor, with caves that plots for the search of light and protection, from here on there are countless examples of land use to create a safe place: the huts shaped with the wet ground, the tents of the nomads created with earth and plant elements, the stilt houses that defy the marshy areas making them habitable, the Trulli (Figure 1), the underground cities and not least the spectacular example of Matera.

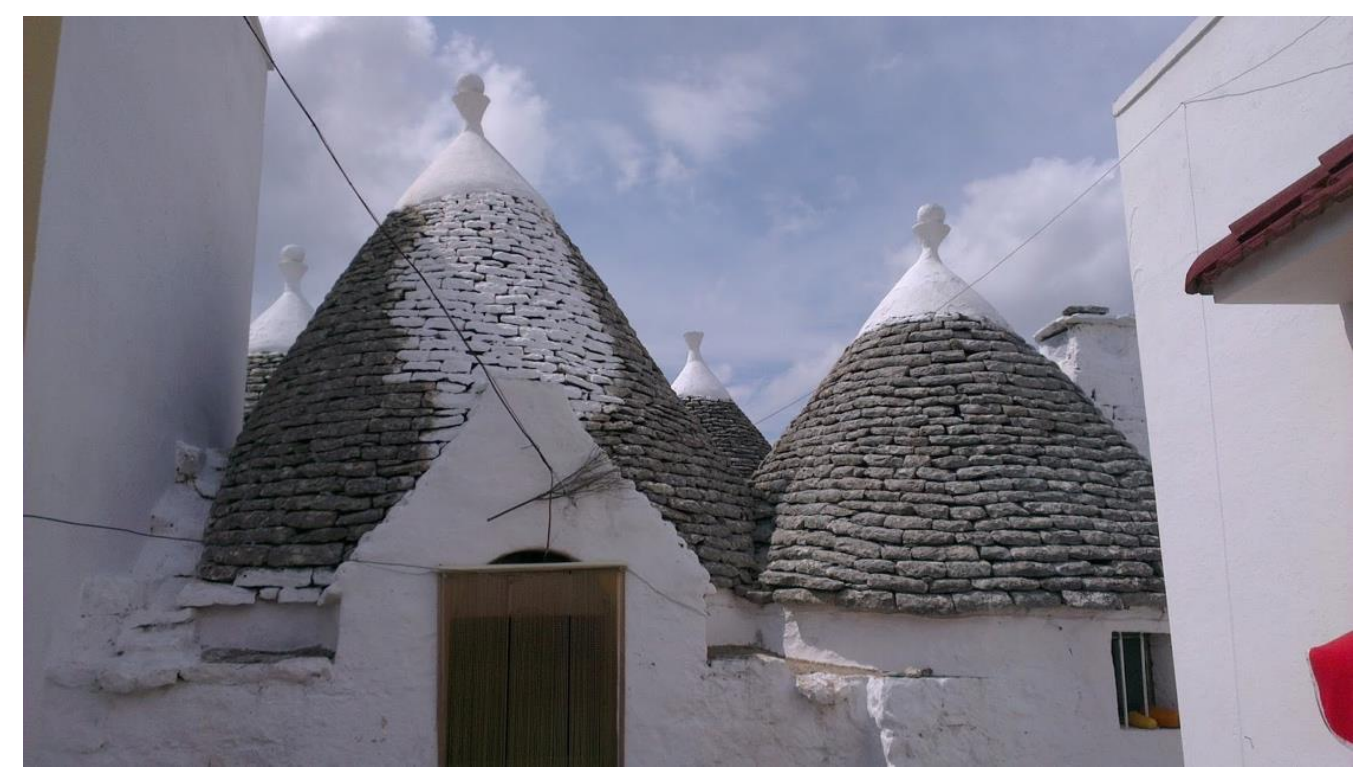

Figure 1. Trulli Matera Italy

Source: http://minervanewscrispiano.blogspot.com/2017/09/.

With the evolution of man, his techniques and design skills have evolved in search of increasingly safe and efficient buildings that have brought the disciplines to a global complexity even in representation. Quite the opposite, in the contemporary world there is a search for simplicity in communication and expression of phenomena.

Why before there was not the need for consensus increasingly required today, in all fields, including architecture, urban planning and landscape? 


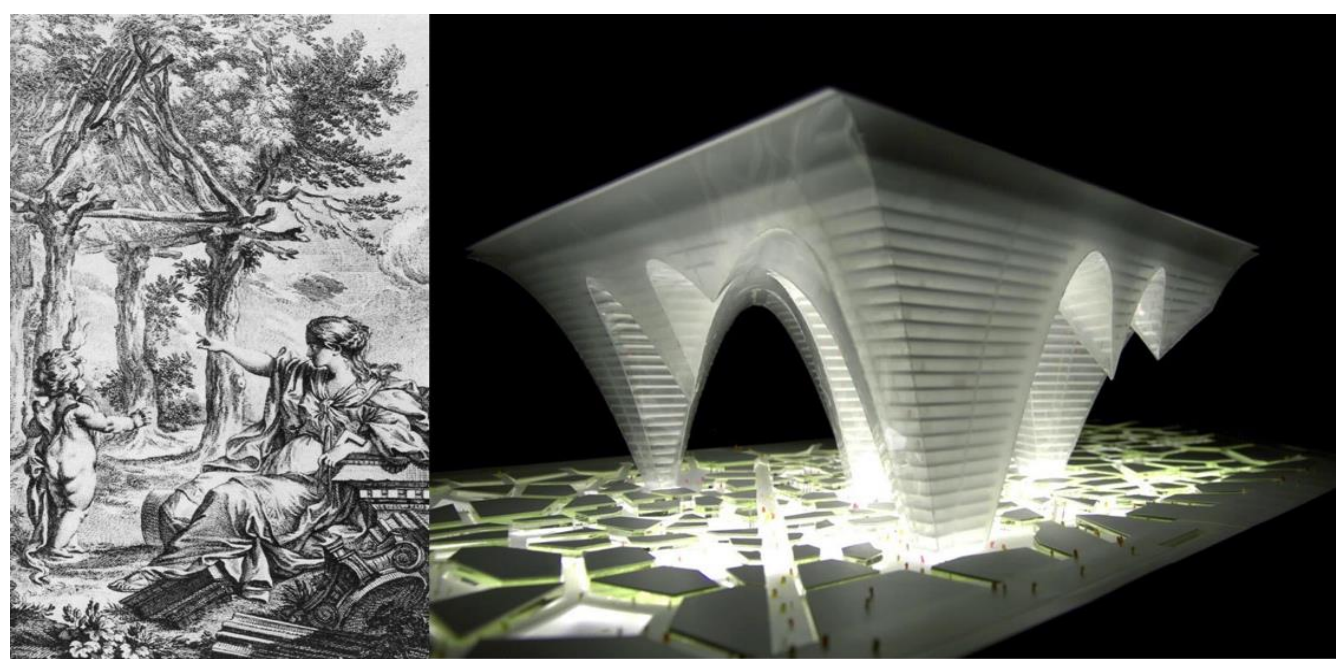

Figure 2. Marc-Antoine Laugier, Essai sur l'Architecture [Essay on Architecture,] Cover Image; Bjarke Ingels Group: The Pillars of Bawadi, Dubai (UAE), 2007 Source: https://big.dk/https://big.dk/projects\#projects-baw.
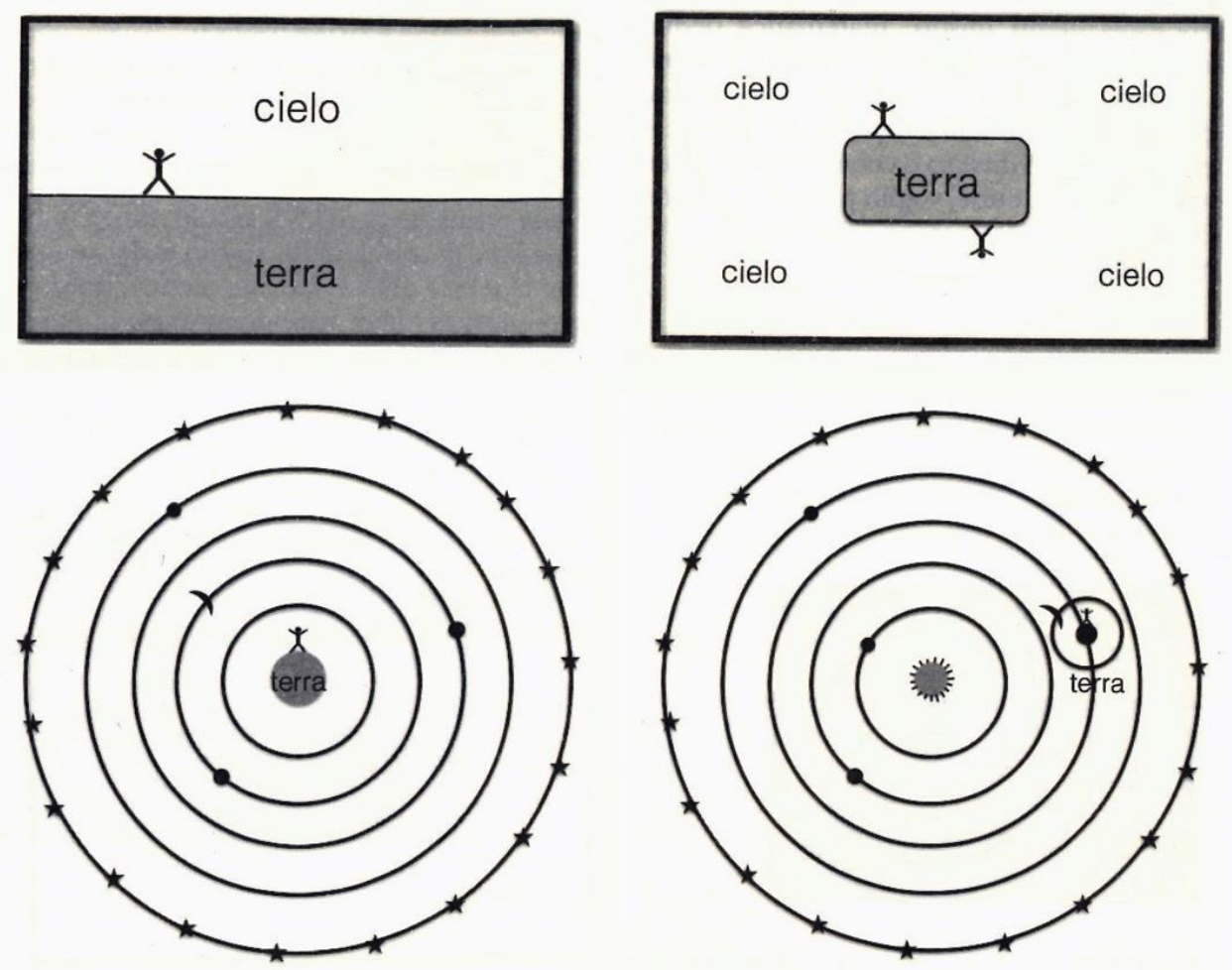

Figure 3. Evolution of the Solar System: 1. Under the Earth, Above the Sky 2. Anaximander Revolution: The Sky is around the Earth 3. The Shape of the Earth is probably a Sphere (Parmenides, Pythagoras, Aristotle) 4. The Great Scientific Revolution of Copernicus: The Earth is not at the Center of the Planetary System Source: Rovelli (2014), 32-34. 


\section{Methodology}

Simple drawings were used by Carlo Rovelli in "Seven short physics lessons" (2014) to describe the architecture of the cosmos. "The reason is that science, before being experiments, measures, mathematics, rigorous deductions, is above all visions. Science is primarily a visionary activity. Scientific thought feeds on the ability to 'see' things differently than we saw them before.",

Beyond the important visionary aspect always inherent in the architecture discipline, a careful analysis of the modes of representation from the past to the present has been conducted, highlighting the similarities and differences that as a logical consequence, has generated a greater awareness of what is happening today. The architecture, landscape, urban planning, computer science and other disciplines merge and push extreme evolution. In the field of city planning, clarity and simplicity are sought in the representation that is opposed to the formulation of increasingly complex shapes that challenge the limits of the territory and the rules of static.

A critical examination of the development of disciplines, such as landscape, urban planning, and architecture, through their design and representation, is at the center of this work, based on the analysis of contrasts and contradictions, but also of correspondences and connections to highlight the complexity of each historical period, focusing on the contemporary. To illustrate the initial thesis, examples of application of tools and technologies from the past to the present have been used.

"I have rebuilt a lot: and reconstructing means collaborating with time in its 'past' aspect, grasping its spirit or modifying it, almost reaching it, towards a longer future; it means discovering the secret of the springs under the stones (...), touching past and future centuries in my games of stone: the walls that I shore up: hands that do not exist yet will caress the stem of these columns."

The design of the city is an action that man has always done and that the various cultures and populations have developed by creating different rules: orthogonal grids, main axes, concentric patterns and the most varied forms. In general, the development of new settlements is determined by the design of new infrastructures and new axes, from the creation of new lots and therefore new buildings.

Today the landscape and the cities appear to us as a stratification of elements, which only in some cases were born at a table, much more often as an overlap of parts and completion of empty portions.

The representation has evolved over time to the same level as the architectural language; in architectural composition it is a fundamental tool to succeed in the creative process, to communicate it and finally to realize it.

2. C. Rovelli, Sette Brevi Lezioni di Fisica (Milano: Adelphi, 2014), 31.

3. M. Yourcenar, Memorie di Adriano (Paris: Librairie Plon, 1951), 121. 


\section{The Theme in its Historical Evolution}

The Romans, whose more or less complex signs still characterize the western landscape today, embody a remarkable evolutionary step in the conception of the project through both its representation and its realization, reaching a degree of complexity in the design surpassed only by the engineering calculations of the iron and glass of the industrial revolution, besides the new parametric design that sets different rules to the contemporary world.

The Roman roads are not adapted to the landscape, but there overlapped, draw as much as possible straight, they crossed the country with massive structural works, passed marshes with monumental bridges and viaducts, engraved with the hills halfway cuts by changing the topography of the site.

"Building, means collaborating with the earth, imprinting the sign of man on a landscape that will remain forever modified; contribute also to the slow transformation that is the life of the city itself. How much care, to devise the exact location of a bridge and a fountain to give the mountain road the cheaper curve that at the same time is purer!"

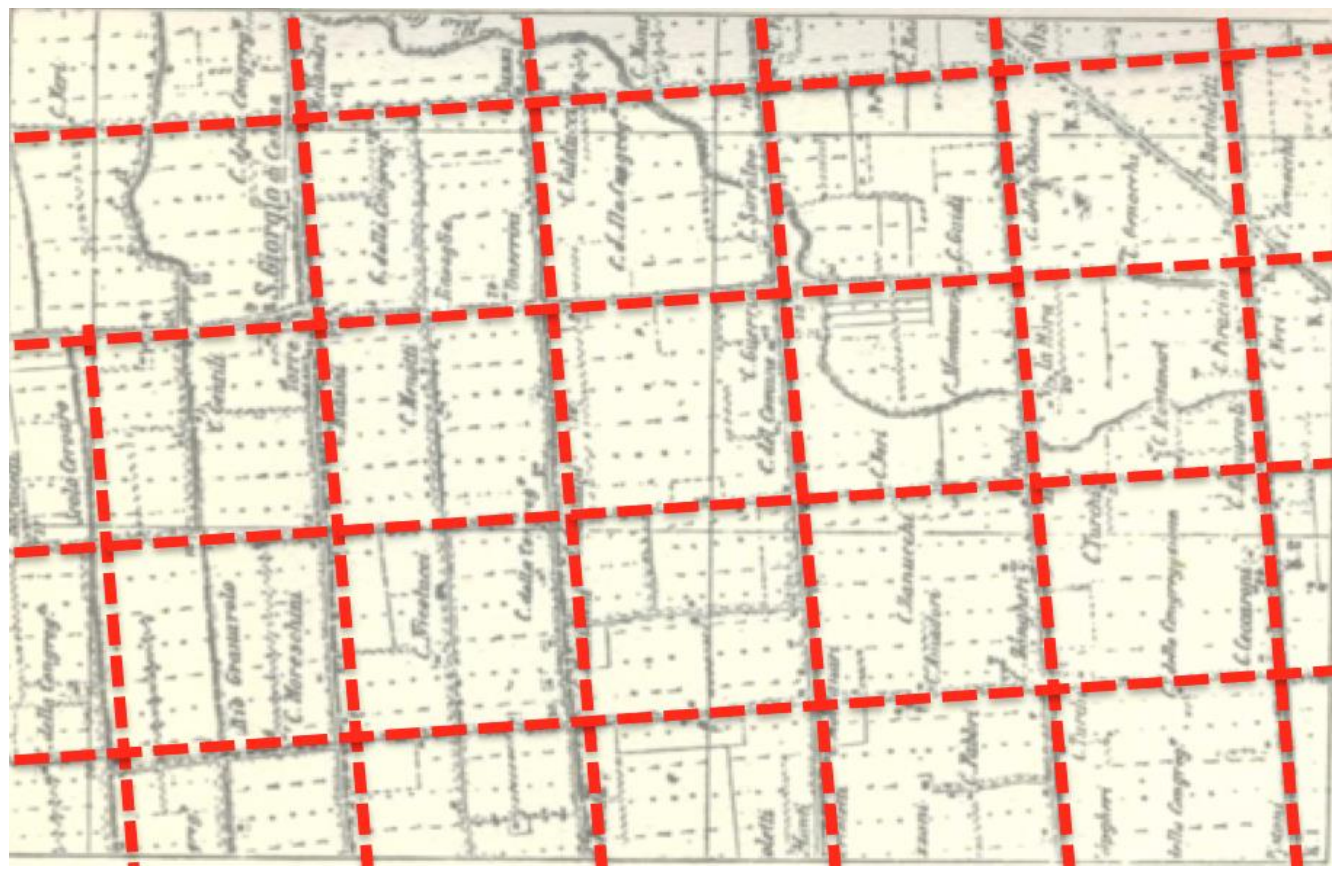

Figure 4. Roman Cardo-Decumanus Scheme

Source: Graphic re-processing by the authors Burlando and Grillo.

The camps and military posts, located along the route at a regular distance between 10 and 20 miles, imposed in the lowlands the directionality of the centuriated mesh, originally used for the organization of agricultural fields. The territory was modified according to an orthogonal grid of roads (see Figure 4)

4. Ibid, 120-121. 
canals and agricultural plots, often coinciding with the four cardinal points to the point that Goethe called the Roman landscape "Second Nature that works for civil purposes". The Ceturiatione, which mainly characterized flat areas and which in many cases can still be observed today, is an element resilient to transformations. In this regard, the Sereni in "The History of Italian Agricultural Landscape" argues that there is a "law of inertia of the agricultural landscape" that makes the signs once fixed tend to perpetuate, even when the technical, productive and social relationships that have influenced its origin have disappeared.

The example of Villa Adriana (see Figure 5) is in contrast with the Roman way of infrastructuring the territory: in the grandiose landscape complex there is a natural adaptation of the buildings to the altimetry of the place. Among the individual architectures, re-enactment of buildings visited by Emperor Hadrian in his travels through the vast Roman Empire and conceived according to the rules of order and symmetry, there is only a visual link, without large land movements necessary to adapt each new object to the pre-existing orography.

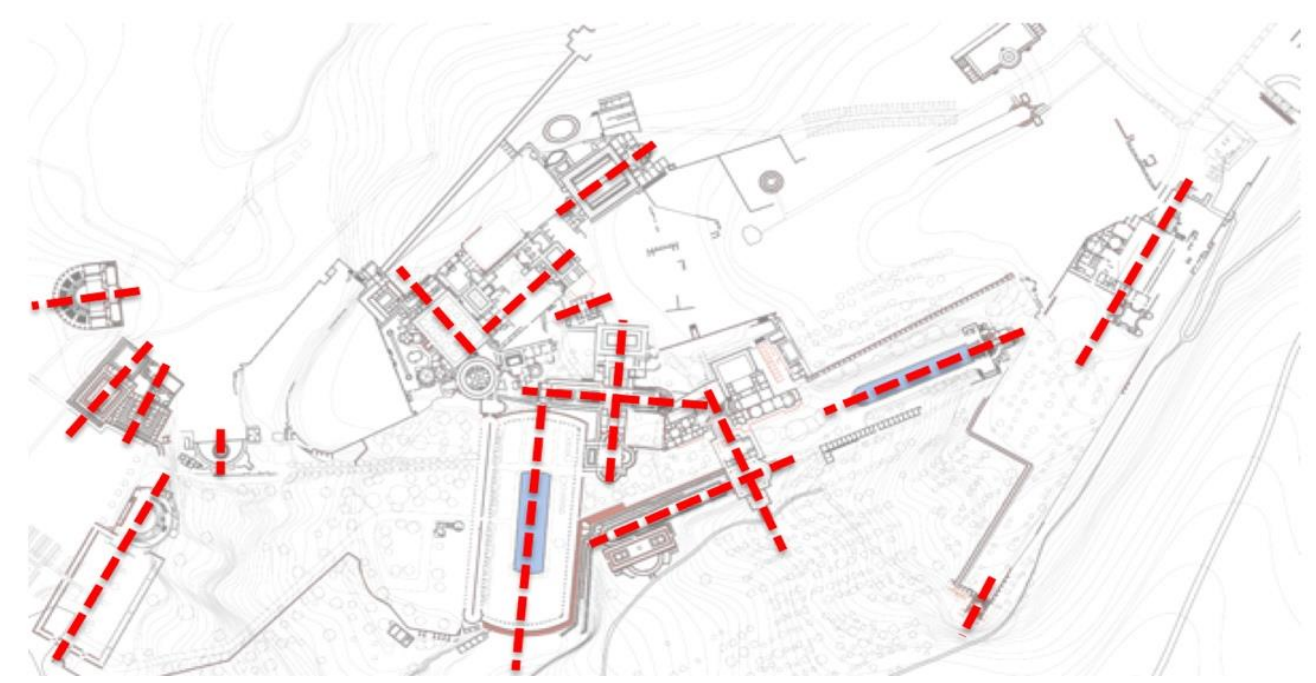

Figure 5. Planimetric Scheme of Villa Adriana Highlighting the Symmetry Axes of the Individual Buildings

Source: Graphic re-processing by the authors Burlando and Grillo.

Although Greek architecture was undoubtedly revolutionary and magnificent based on simple and more intuitive principles; with the trilith, the Romans began to develop a real conception of design and ability to shape the space, so they also stood out on the architectural scale. The Romans, as mentioned, built architecture of all kinds, took care of useful works of urbanization, architecture for the worship of gods, honorary buildings and entertainment, theaters, villas and palaces that still amaze us for their magnificence, but the aspects that most interest this study are the techniques and the skills with which they were made including the complex representation of architectural design, which goes hand in hand with a technological development; new forms were developed: the arch and the vault that allow to cover immense spaces and create resistant walls of great thickness, the complex and various techniques of different wall hangings depending on the use 
and made stable by the formulation of the mortar. At this point it is crucial to mention the Treaty of Vitruvius De Architectura, for the first time in the history of architecture is formalized by creating an essay on the various techniques and forms but especially on the architecture inherent meaning sanctioning the hinges of the latter. Vitruvius at the beginning of the first volume wrote that architecture was born simultaneously from Fabrica and Ratiocinio, the techniques developed were fundamental for creating extraordinary buildings and shaping spaces but it is absolutely necessary that at the base there is a theoretical-intellectual thought. Without this there is only one artifact that does not include the complexity of architecture, which is the univocal fusion between Utilitas, Firmitas and Venustas. Moreover, in the De Architectura, Vitruvius clearly wrote of composition defining Ordinatio Dispositio and Distributio the canons to follow for the right choice of the site, the determination of plan and elevations with basic modules and the right structural sizing. These must merge with the Symmetria, Eurythmia and Decor.

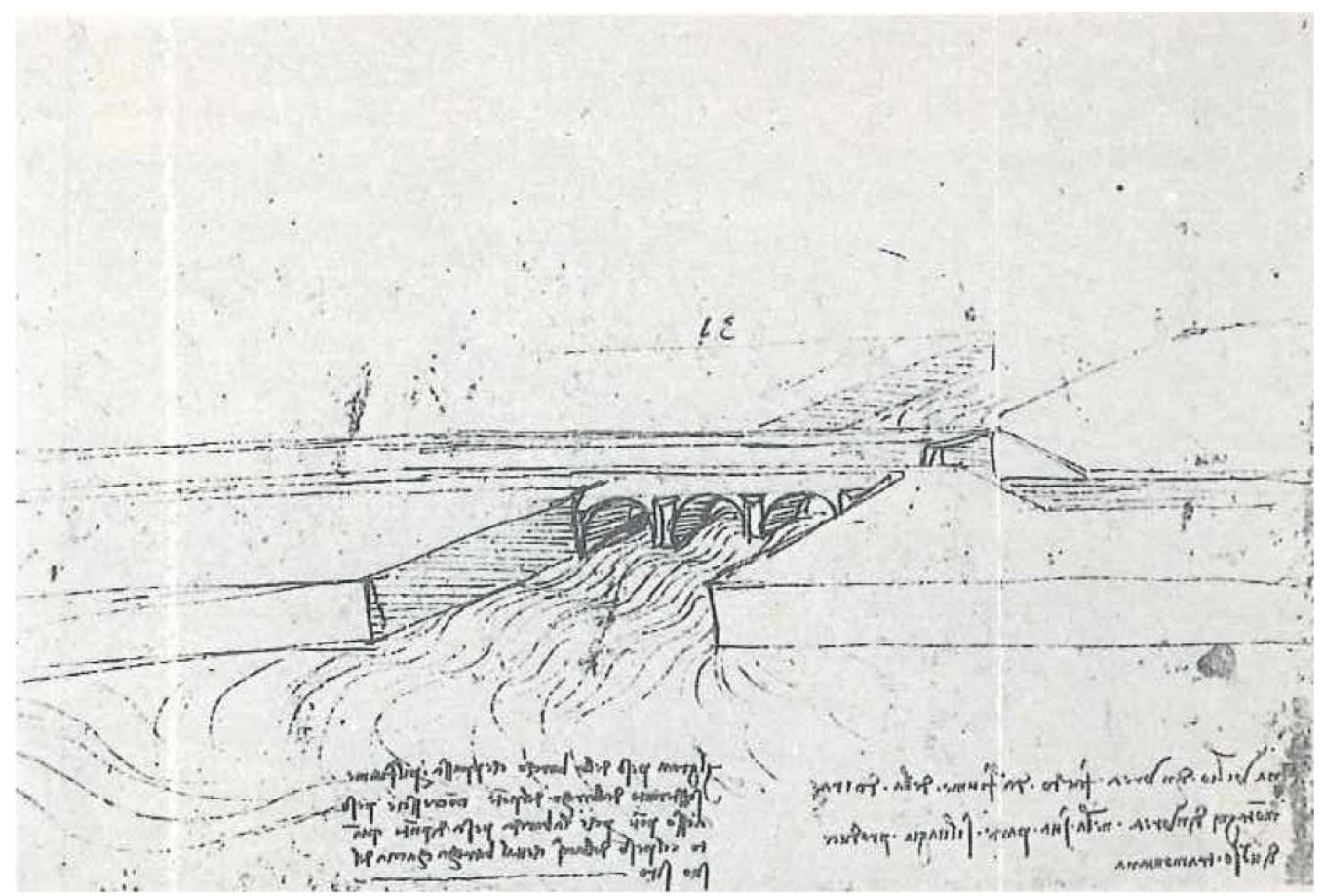

Figure 6. Leonardo da Vinci: Sketch of the Naviglio Hydraulic Solution, in Codex Atlanticus

Source: www.flickr.com.

After the pause of the Middle Ages with the spread of the use of perspective, the geometrical design imposed itself again modifying the territory, not exclusively urban, in the realization of squares, gardens and cities and not only ideals. ${ }^{5}$ In this case the impact was less than the imposition of the rigid mesh of the

5. Vitruvius introduces Scaenografia, which is suggestive design of the building as a whole, called in late Latin Perspectiva. Vitruvius in the preface of the seventh book states that the perspective view has already been defined by the philosophers Democritus and Anaxagoras in the fifth century BC. as a natural principle of human vision. M. Spesso, Teoria dell'Architettura - Dal V secolo a.C. al Barocco (Padova: Libreriauniversitaria.it, 2011). 
Centuriatio on the territory and the ingenious introduction of the arc in the art of construction.

A separate chapter could be dedicated to the multifaceted genius of Leonardo da Vinci, Ludovico il Moro's chamber engineer, who worked in Venice, Lombardy, Tuscany and at the court of Charles d'Amboise. An evolved figurative picture of how to design his time can be had through his work: graphic annotations, sketches, models, drawings and notes; important information on tillage techniques, locks, embankments and channels. For example, even today in Ivrea the hydraulic arrangement of the Naviglio can be observed; the corresponding design sketches are preserved in the Codex Atlanticus (see Figure $6)$.

With the application of the theories on the city-park the imposing and immense transformations, which Le Notre imposed on the French landscape, can still be observed today (see Figure 7). The greatest landscape architect of France, not only of the seventeenth century, applied in his interventions the Cartesian rationality with a complete dominion of nature by man, reinterpreted the tradition of the Italian garden and the French models to him earlier, fused the various experiences in a unified vision with magnificent works of landscape architecture. He created a synthetic and rational work, based on an apparently simple design, where the amplitude and the essentiality of open spaces predominantly dominated the building. The parks of Le Notre, with their vast expression of absolute monarchy of Louis XIV, were designed to be populated by many people, to serve as a framework to lavish court festivities and visible from above. 'Forcer la Nature' was the imperative of the Roi Soleil which led to the radical transformations of landscapes, to the diversions of watercourses, to the leveling of wooded hills and massive reforestation. If the seventeenth-century French parks represent the most splendid expression of absolute monarchy in history, their construction was undoubtedly made possible thanks to the use of innovative methods and instruments introduced by the military architects described in the Mollet, Boyceau or Dezallier treaties, but also thanks to the mastery of design, the use of metric scale and perspective.

On the one hand it was important to perfect the operations of surveying the shape of the land and the water thanks to the measurements and leveling, "setting up plants and risers" that allow to recognize "if the arrangement is gracious, if the parts are convenient the one with respect to the other "and finally to evaluate" the work before it is realized." 6 Then prepare the ground, regularizing the conformation thanks to the measurement and the art of building terraces, terraces and slopes, art directly marked by the engineering of the fortifications from origin to a sensibly new space. This was mainly made possible thanks to the evolution of measurement and construction tools applied to the construction of the garden: the compass, the line, the team, the plumb line, spirit level, the bevel and the astrolabe; for example, the use of a 16th century English invention spread: the tablet of the topographer equipped with alidade, which allowed to trace the angles horizontally directly when the target was taken.

6. J. Boyceau de la Baraudière, Traité du Jardinage Selon les Raisons de la Nature et de l'Art (Paris: Hachette Livre BNF, 1638), 68. 
On the other hand also a complete mastery of the design and use of the aerial perspective with effects of fading and reflection for the presence of water premise complete control of the open space and the creation of grandiose works. "It reigns there, above all through symmetry" 7 and the compositional order of the terraces from which the view extends to dominate the whole.

The vision defect, recognized by the laws of optics, becomes the "natural" requirement to be used for simulations. Among the gimmicks adopted the approachers are: the avenues too long discourage the visitor, the designer will then pretend by artifice to approach the final stretch by narrowing or closing the end and thus subtracting a part from the view ${ }^{8}$. To determine the extension, however, if the garden is large, it will be possible to make the view open to the surrounding countryside. If, on the contrary, the garden is small, the designer will try to "make sure that all the avenues are not open to the eye from one end to the other." 9

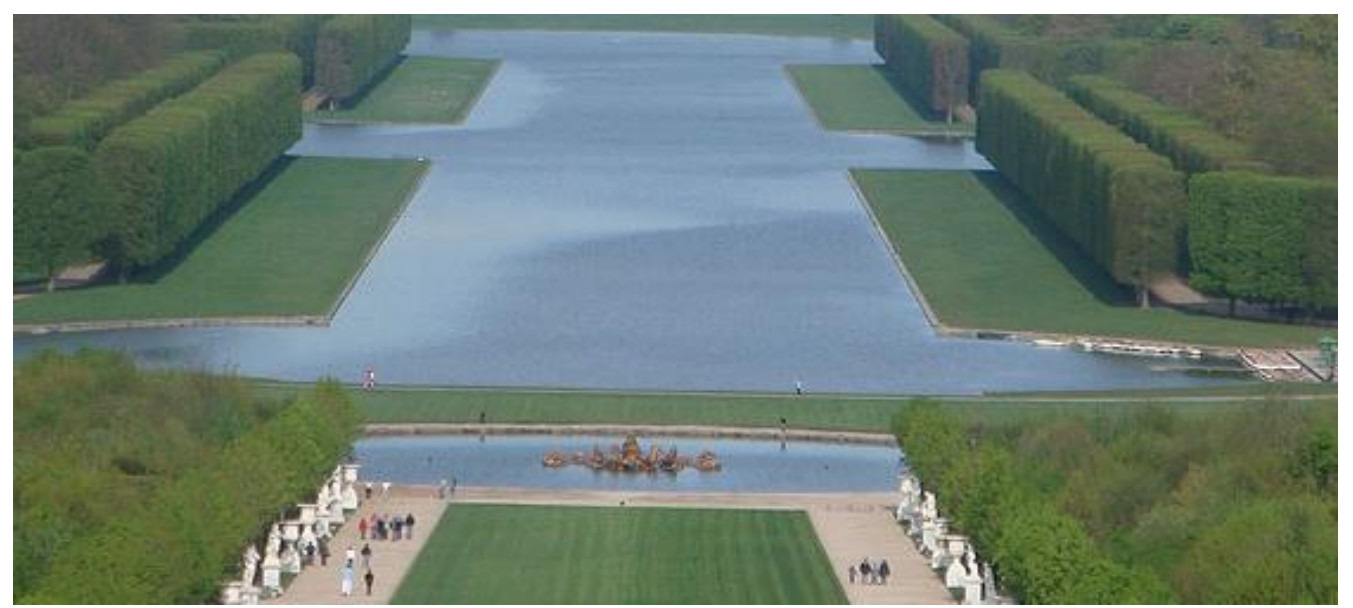

Figure 7. Gran Canal View, Versailles @ 2009- M. Lagneau

Source: www.flickr.com.

In the mid-eighteenth century Italian example of a great transformation was imposed on the Campania region with a complex design. The Lenotriano model was reproduced in the Reggia of Caserta reinterpreted by Vanvitelli. The landscape composition develops along a single perspective axis, which runs along its entire length, between flower beds, pools, waterfalls, sculptural groups, prolonged in the background, in the wooded hillside of oaks. The elements of the park come together in a happy synthesis of different cultural influences, of Italian and French experiences re-elaborated together: the perspectival expansion of the space, inspired by French, obtained by using the dissolving and reflecting effects produced by the large water surfaces developed on the axis tends to infinity; the Baroque style game of the rocks,

7. D. D’Argenville, La Theorie et la Pratique du Jardinage (Paris: Hachette Livre BNF, 1709), 13.

8. F. Boudon, "Nascita del Giardino alla Francese: Cartografia e Storia dei Castelli," in The Architecture of the Western Gardens - from the Renaissance to the Twentieth Century (ed.) M. Mosser and G. Teyssot (Milano, 1990), 121-142.

9. Ibid, 36. 
which are transformed into sculpture in dynamic groups of statuary fountains and water, which assumes, along more than a kilometer path, different shapes, sliding flat or erupting from the artificial reefs. The Renaissance axiality of the only clear directrix, which connects palace, garden and landscape, is enriched in the composition of a new perspective artifice: bending with a rhythmic progression, between the palace and the hill, it allows to perceive the central motif of the water, of the waterfall, of the canal, in all its length, in a single view, from the shadow of the wooded hill, to the sunny and flat area of the garden, from the natural to the artificial, from the natural landscape to the geometrical space tamed by art. In the work of Vanvitelli to obtain the perspective expansion of space with reflecting effects of water, a compositional principle was adopted, described by Dezallier and already used by Le Notre: the Quercus ilex wood behind the water chain makes the reduced space (maximum width 120 meters) appear much wider. To make the water features along Mount Briano behind the Reggia, Vanvitelli imposed another indelible mark on the Campania territory: an aqueduct of 30 kilometers, in tunnels and on complex viaducts up to 60 meters high with three orders of arches, which implies difficult plumbing studies with complex drawings of insertion into the landscape.

If by the invention of printing the knowledge is spread more easily, but only with the Enlightenment began the first true globalization of knowledge process, which is closely related to synthesis to facilitate mass communication. In this vein the following example of simplification in the representation of a complex reality can insert. This consists in the introduction of the use of the level curves to draw the morphology of the territory, especially in the case of steep terrain. Despite the advanced use of perspective and the progress made by cartographers after the sixteenth century, the representation of a site had not reached the same evolution. With the cartography, it was difficult to make the idea of a relief if not through the design of the shadows, difficult to represent in correspondence with constructed elements. In 1668 the Marquess of Louvois proposed to Louis XIV to realize, for all the strongholds that were multiplying under the impulse of Vauban, extremely precise models, indicating everything that was in the various citadels: military buildings, civil houses and the surrounding agricultural landscape. The tradition of making three-dimensional models also continued with the kings who succeeded each other until the nineteenth century. Among them the most significant is that of La Spezia. The latter, in fact, was created on the basis of a map on which the level curves were drawn. Probably in the case of the landscape overlooking the Gulf of La Spezia (see Figure 8) the sequence of many parallel lines, corresponding to the terraces, suggested the use of the 'level curves' as a way of graphically representing a relief. This technique brought simplification and clarity in the representation of the territory, so useful that even today it is used to reproduce the slope in all the cartographies, with a differentiation in the number of level curves depending on the scale of representation. ${ }^{10}$

10. R. Ambroise, P. Frapa, S. Giorgis, Paysages de Terrasses (Edisud: Aix-en Provence, 1989), 76-77. 


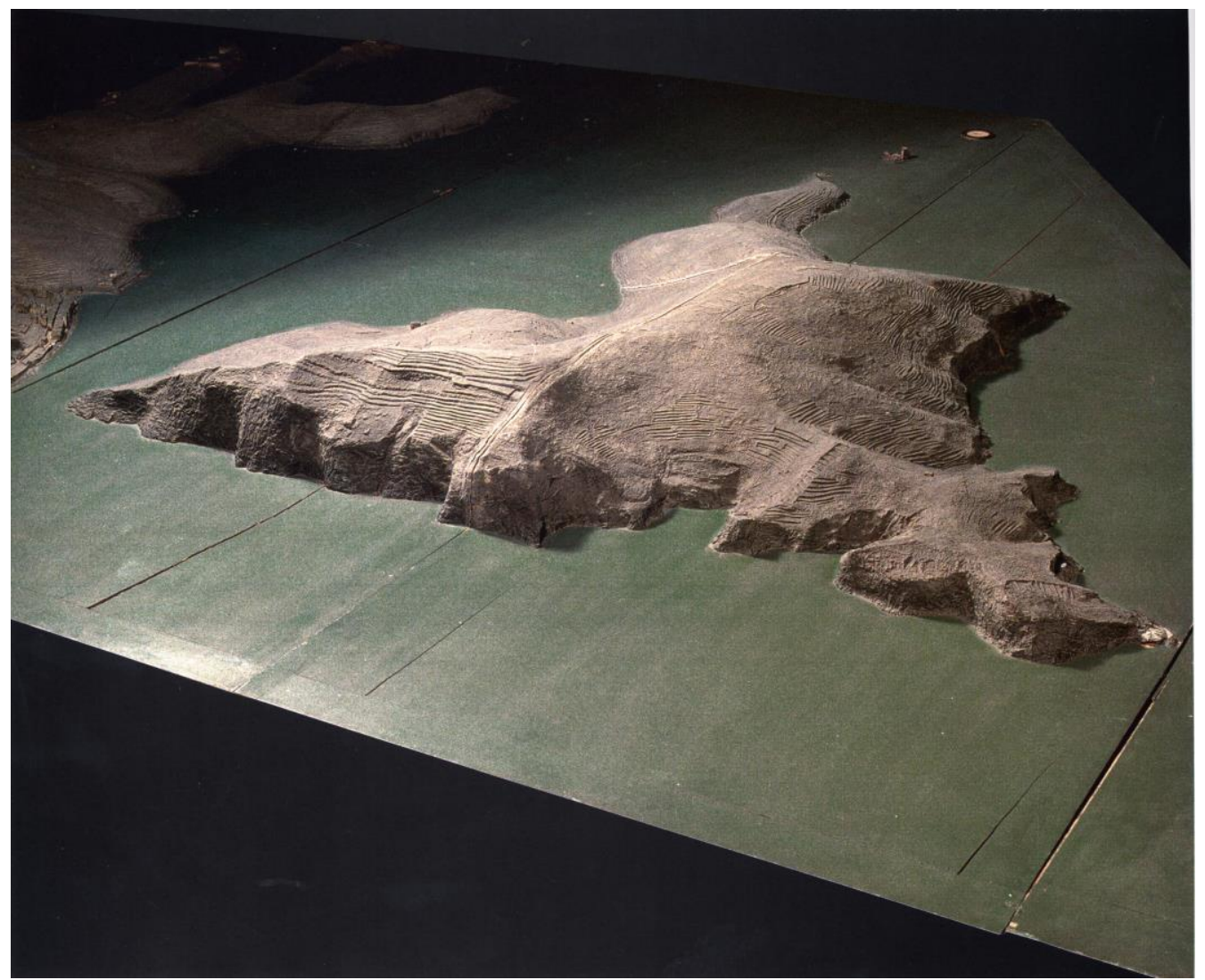

Figure 8. Model of the Palmaria Island Created by the Topographic Brigade of P.A. Clerc, Using a Plan-Relief Curves Drawing, La Spezia/Sur le Golfe de Genes (Italie), 1811

Source: P. Burlando (2010), 33.

The simplification process to allow data communication to all developed further: in this regard, the concept of global participation can be introduced, today at the center of our political-cultural debate. This excursus focuses on the idea of sharing expressed by the invention of the subway map as a synthesis of a more complex cartography to be universally readable by each individual. The starting point dates back to 1931 with the innovative idea of Harry Charles Beck to redesign the map of the London Underground (see Figure 9), using only straight lines connected by segments. This scheme, which does not correspond to the topographical reality, simplifies the interweaving of the numerous underground routes. Nevertheless, this representation is readable and understandable at a glance. Inspired by this theme, the writer Baricco explores the theme of "truth", between reality and representation, between phenomenon and perception thanks to surprising relationships with Dante, Beethoven, Kant and Leopardi. ${ }^{11}$ Before Beck in 1863, a map was created for the inauguration of the first section of the London subway, where the open spaces are depicted in scale together with the underground railway lines, with the peripheral areas almost illegible, because they are very

11. A. Baricco, La Mappa della Metropolitana di Londra. Sulla Verità (Mantova Lectures, 2017). https://www.raiplay.it/programmi/mantovalectures/. 
decent in the representation. The map indicated the location of the underground stations, but these were irrelevant to travelers who wanted to know how to get to the nearest station to a place located on the surface. In 1933 Harry Beck, who was an employee of the London Underground Signals Office, produced a clearer and more legible map, making a summary redrawing the train trajectories only with straight lines, perpendicular or 45 degrees and each station equidistant from the other, without no reference to the real except for the blue stretch of the river Thames. To make the map clearer and to underline the links, Beck made a difference between the ordinary stations marked only with notches and the interchange stations marked with diamonds. This represents a simple and replicable model, which even today has not been exceeded for its degree of innovation, so much so that it is used universally to draw all the maps of all the subways in the world.

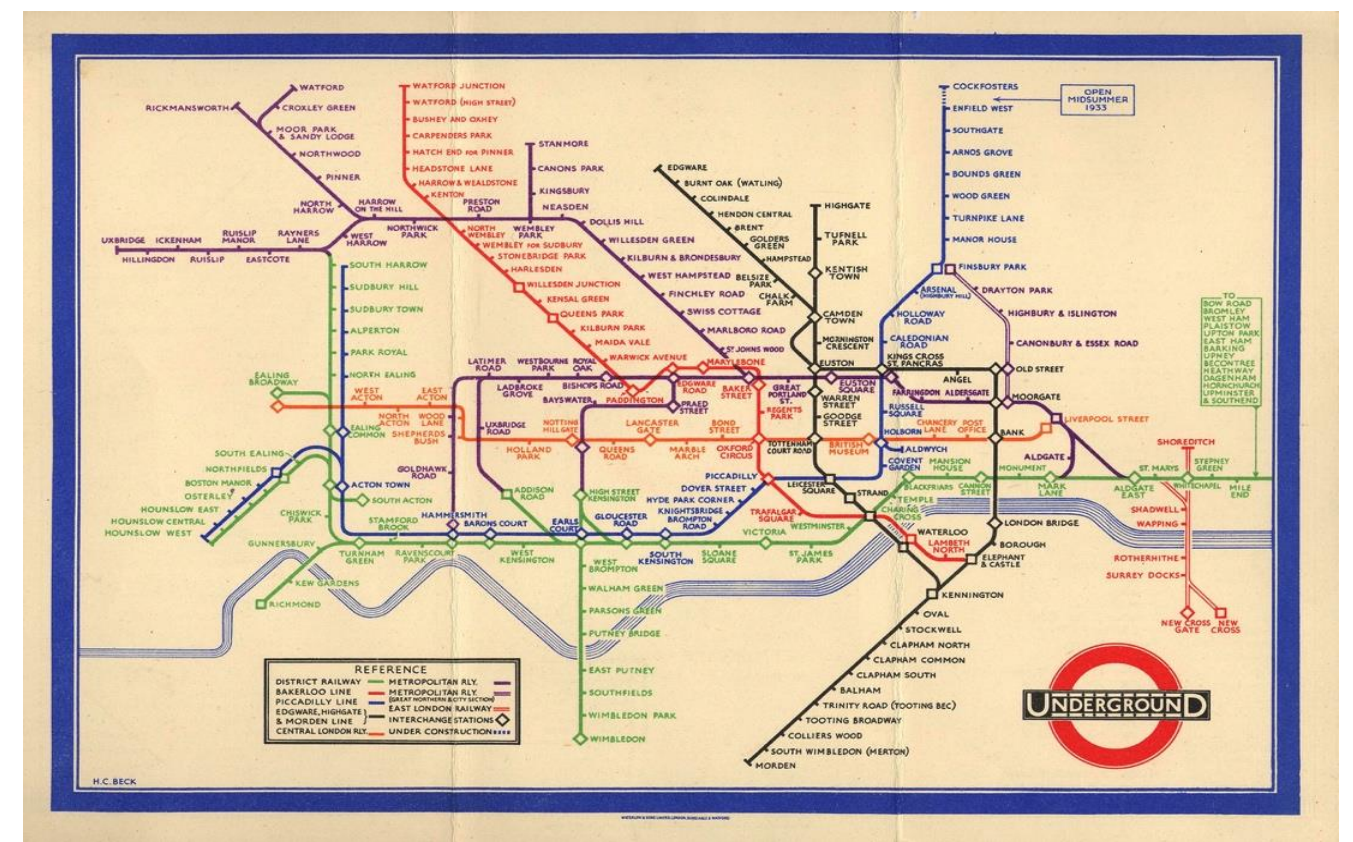

Figure 9. Harry Charles Beck: The Map of the London Underground 1931 Source: http://www.abc.net.au/news/2013-01-10/london-underground-map-1933/4459286.

\section{The Theme in Contemporary Age}

'To compose is to bring together several things to make just one,12

A peculiar phenomenon that has been witnessed in recent years, which inspires and surpasses past experiences (ideal cities, ...), is represented by the creation of new cities in the United Arab Emirates where the limits do not exist: the territory is designed with artificial forms, the coastline is remodeled with figures and elementary representations, ever higher and bizarre skyscrapers are

12. E. N. Rogers, Esperienze di Architettura (Torino: Einaudi, 1958). 
raised with extreme rapidity, requiring considerable economic resources and technological capabilities.

This search for complex shapes in buildings takes place all over the world, it is now a challenge between the greatest architectural firms to use parametric design to design new buildings. This technology allows to overcome the limits of the past and to create daring shapes that free themselves from simple geometric shapes, creating a new contemporary language. It is clear that without a proper cultural and intellectual background it is only a game with forms.

The extreme search for new territories and new resources has its negative sides: the change of territory by man has very high costs and risks, we need to enhance its potential without forgetting the limits.

A concrete example of the above is the Dubai waterfront: in the satellite image (see Figure 10), we see the contrast between the situation of the city in 2000 and 2016, it is clear how the hinterland has remained almost unchanged, while the sea has been filled creating geometric shapes and the famous project of artificial islands known as 'The world'.

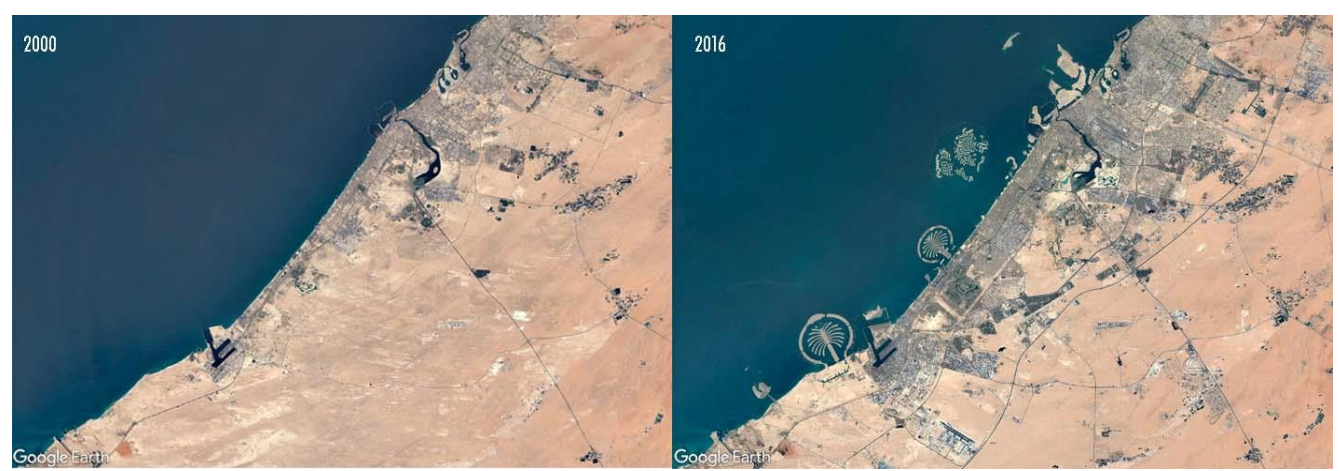

Figure 10. Satellite Images of Dubai Compared (from the Right 2000-2016)

Source: https://www.google.com/maps.

On the other hand, the interventions made necessary to adapt the cities, the coastal and fluvial areas to the problems generated by climate change, rising water levels and increasingly widespread urban flooding, are quite different. In this case the immense and expensive transformations are justified for reasons of public security.

"In New York a new integrated and reciprocal organization of natural systems with the city's current infrastructure was developed to the contend with incremental sea level rise. In attempt to align natural and hand-made elements, the new model of urban infrastructure can transform the city both in use and experience.",13

According to the current trend, it was estimated that in 2100 , if no action is taken, $61 \%$ of Power Manhattan will be underwater. In the proposed strategies,

13. S. Cassell, S. Drake, A. Yarinsky, "Manhattan - New Urban Ground," Topos: European Landscape Magazine 73, no. 82 (2011): 82-87. 
ecology and infrastructures form an interconnected system: porous green streets and a graduated edge (see Figure 11). The above-and below-ground performance of the city can be supported by a newly integrated and mutually beneficial infrastructure. The idea is to make an internal system of porous roads work with an external marsh system. Up to the reach of a Category 2 Storm surge, the streets are rebuilt as a connected series of porous conduits that drain storm water without impending vehicular circulation. This highly efficient system includes existing services (water, sewer, gas and electric) relocated in accessible waterproof vaults beneath the sidewalk. The individual green streets are calibrated to accommodate three different carrying capacities for absorption, retention and distribution of water. On the edge of the island, three interrelated high-performance systems are constructed to block higher sea levels and mitigate storm surge force and flooding: a productive park network, freshwater wetlands, and tidal salt marshes. This continuous layered ecosystem attenuates waves, manages the urban watershed, filters interior surface runoff, enhances biodiversity, and introduces a new system of public green space. The morphology of this graduated edge adapts to the unique urban conditions on the East and the West sides of Lower Manhattan. The sheltered urban estuaries are comprised of salt and freshwater marshes fed by the porous green streets and the harbor. Throughout the estuaries are a series of pilesupported walkways, called transverses, which connect city streets and allow the people to occupy the landscape without disrupting the natural habitat. The watershed park improves the quality of public space by mediating between wetland and city. This park will be multifunctional, with spaces linked through a reconstructed West Street. This holistic proposal unites natural ecology and urban infrastructure to create a flexible and adaptive future for Lower Manhattan: New York re-invents itself yet again by developing in tandem with natural systems.

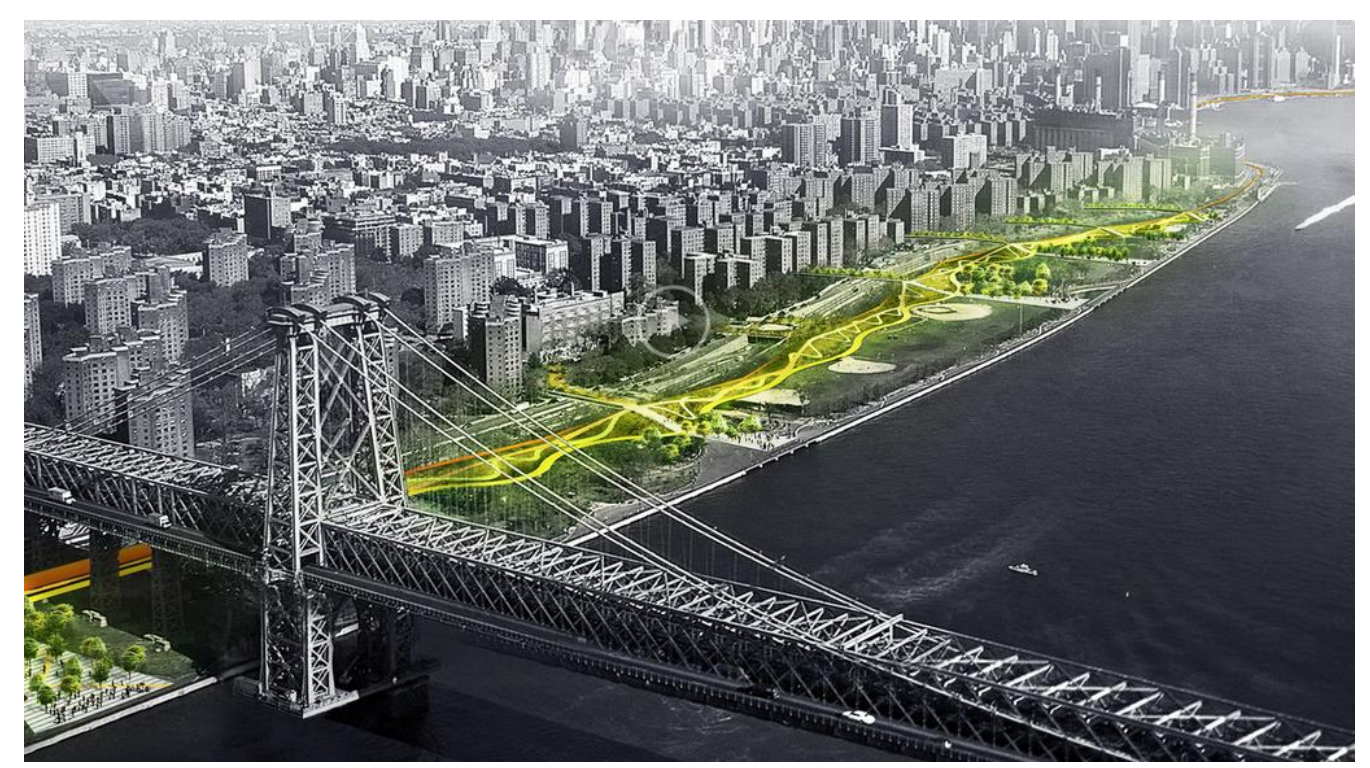

Figure 11. The Big $U$

Source: http://www.rebuildbydesign.org/our-work/all-proposals/winning-projects/big-u.

Turning to the urban scale, the new architectural language of the contemporary age is based on the search for new and extreme forms; Frank Gehry was one of the 
first architects to experiment with a new way of doing architecture. Its buildings, such as the Walt Disney Concert Hall in Los Angeles (see Figure 12), are a set of fluid forms intersected to create projects that are apparently light.

The language of F. Gehry will be developed by Zaha Hadid and other international signatures.

This research is possible thanks to the use of very complex software and the use of the parametric design.

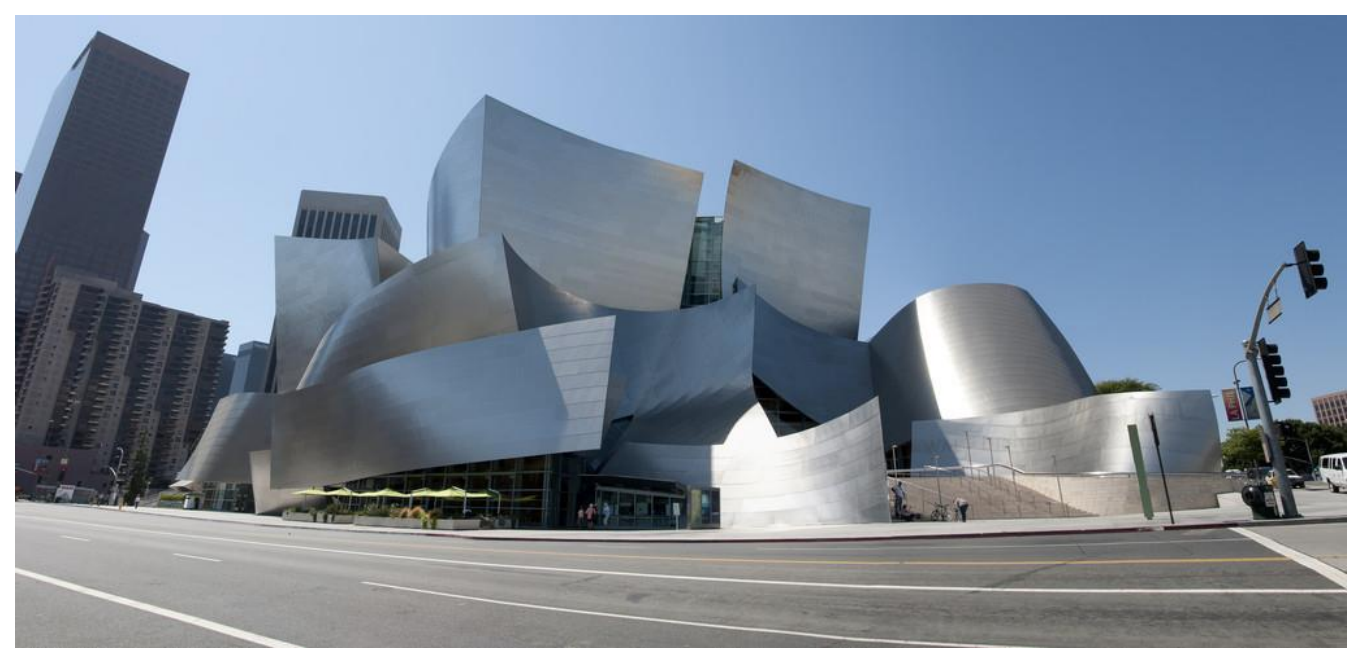

Figure 12. Walt Disney Concert Hall, Frank Gehry, Los Angeles (CA)

Source: https://bit.ly/2RLmzeR.

"Parametric design became an intensely fashionable process in XXI century, as if had existed before. Essentially what it means is that the relationship between elements or structural components of building can be manipulated, usually trough computer programs, to inform and create new and complex geometries. This allows buildings to spring up in remarkable twists and turns, as if unrestrained by the conventions of structure, materials and design. ",14

Zaha Hadid showed how parametric design and art can merge into installations with kinetic effects (see Figure 13). The parametric design exists before computers. Gaudì designed the complex vault through a model, in which to look inside with mirrors, to correct any errors. This shows complete mastery of the working tools. The computers have replaced such models, yet it worked. If the works of Gaudì are almost always incomplete due to the difficulty of totally parameterizing the work of art, with the computer the risk is to go towards too bold daring without concrete foundations.

14. Ibid, 140. 


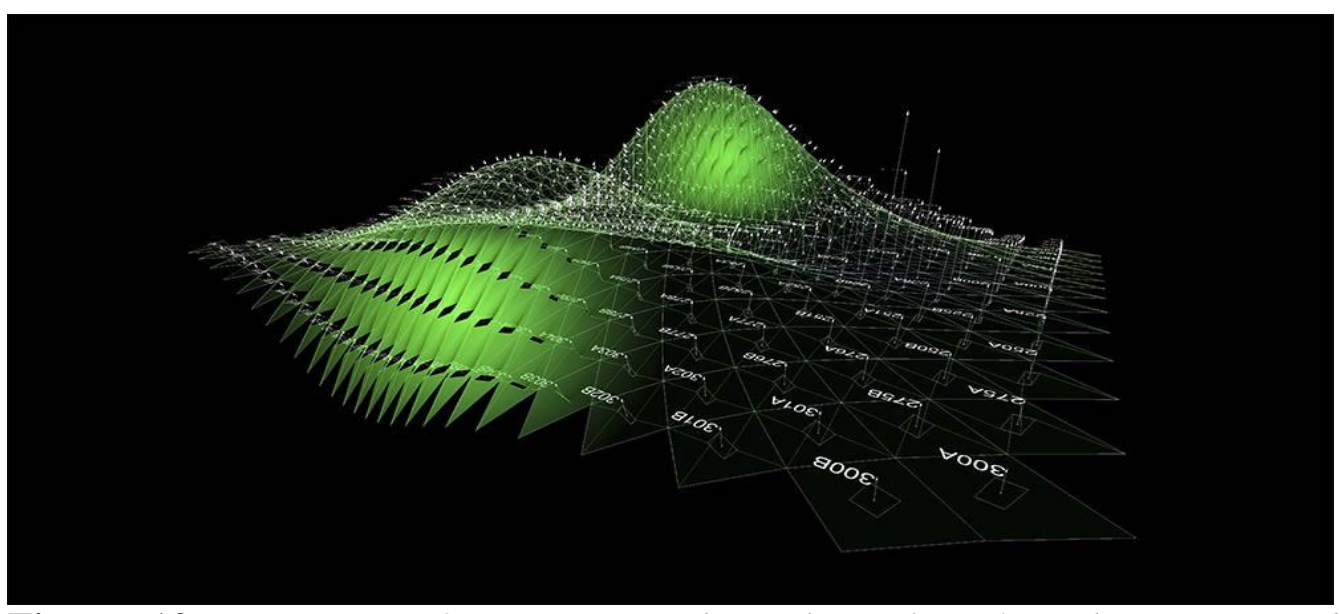

Figure 13. Prototype of a Lamp Made with Tspline for Rhinoceros and Rhomboidal Pattern Realized in Rhinoscript Code

Source: https://www.area-arch.it/data-drivengeometry-mutation/.

In the past there was no need, which characterizes the contemporary age, of understanding and global consensus; for this reason the representation of a project pushes towards forms of communication as simple as possible in order to be understood by everyone.

An internationally renowned architect like Zaha Hadid claims that: "For an architect everything connects. The design of handbag or furniture or cutlery has their challenges, and they're fun to da. I'd love to get some design into mass, lowcost production. I want to be able to touch everyone not just the educated and cultural elite, with a little of what we can do. One of the things I feel confident in saying we can do is bring some excitement and challenges to people's lives. We want them to be able to embrace the unexpected." 15

The new way of designing the city and its elements must be in some way understandable by everyone, hence the need to find clear and elementary methods of representation.

The consent and acceptance of new architectural forms is fundamental for the identification of everyone within the new language. A project or a competition must be shared by the multitude before their realization, the media exaggerated the concept that every public action must be accepted by the population; unfortunately, or fortunately, this phenomenon does not only affect the political sphere, but in some way it should be regulated.

In the architectural world, the use of schematic concepts has become widespread, representing in a linear way the development of a project starting from simple shapes and using actions such as emptying, rotating and adding. Actually, even if the design process is represented in a schematic way, very complex but formally and functionally 'perfect' buildings are obtained, so the generated forms require considerable computational capabilities that are often impossible without the sophisticated design software.

15. J. Glancey, What's So Great About the Eiffel Tower? 70 Questions that will Change the Way You Think about Architecture (London, Laurence King Publishing, 2017), 127. 
Although as regards progress and the creation of a new language in architecture, representation and design are the protagonists. The concept of a building in contemporary architecture is in many cases the search for an increasingly extreme and different form; if you look at the sketches of some great architects such as Gehry, the ideation seems an immediate spontaneous and simple process, or Big (see Figure 14) who, following the functions of exposure and territory morphology, communicates the steps as a logical and inevitable process; the concept that today everyone uses communicates the steps of the composition in a simple and intuitive way, it is an action that was not done before there was no need to justify and accept their architectures, often these representations use ideograms and seek in all ways to simplify the architectural forms obtained; actually, in order to obtain the buildings in question, it is necessary to use very complex planning and calculation software.

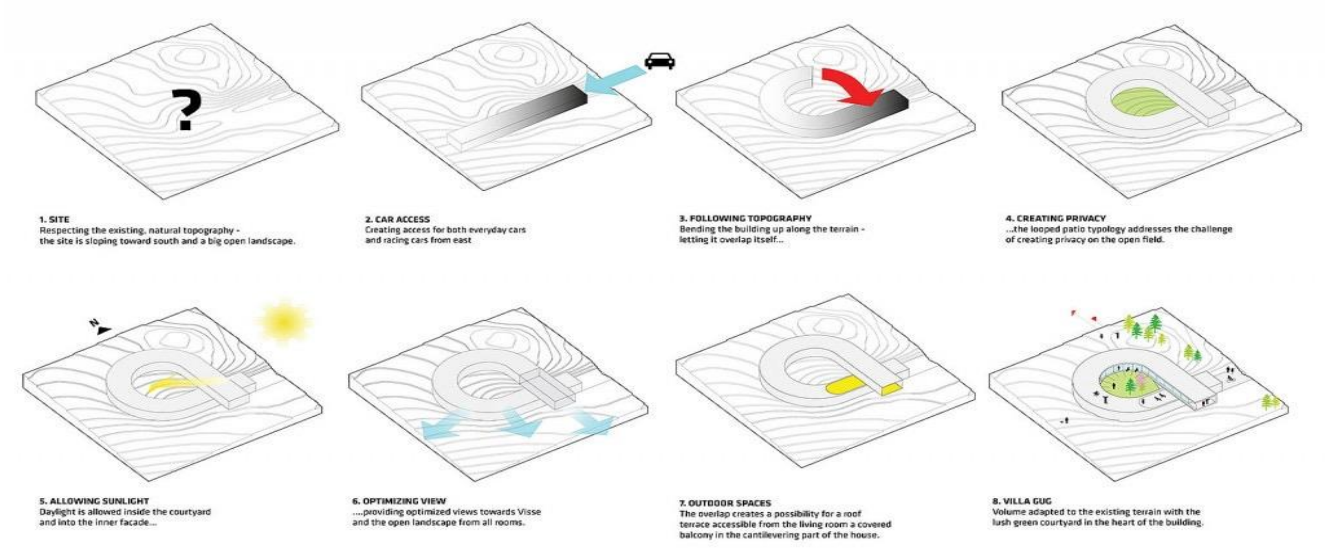

Figure 14. Diagram BIG Bjarke Ingels Group: GUG, Villa Gug, Alborg, Denmark, 2014

Source: http://ctrl-z.it/diagrammi-architettura-big-tutorial/.

\section{Conclusions}

"It is improvising and adapting to unforeseen obstacles, which we make the greatest progress. (...) Instead of complaining about obstacles or failures, we say yes to reality, to the city and to life. Every time we hit against and change we receive a lot. Yes is More." 16

The birth of new and rich settlements in certain areas of the world and the use of increasingly advanced design technologies represent an advanced and innovative system of construction, which should be useful even in more difficult situations, where economic resources are scarce and where slums or favelas overwhelm without rules and without a predefined order. Investing substantial

16. Big Bjarke, Yes is More (Copenhagen: Ingels Group, 2011), 23. 
resources to create shapes and games with figures can have its positive aspects, certainly even in the past if the architects had not dared so much, it would not have been possible to have a work like the Palace of Versailles, still admired and visited by millions of people.

At the center of this study is the evolution of representation in the architectural work; the method for expressing and revealing what happens inside the human mind, to reproduce reality or interpret it, the way to communicate, understood as a process of transformation implemented in the environment both in the design of the city and in the smaller scale of the single building.

These buildings and cities made with extreme designs, the search for new forms, land modification and experiments are part of contemporary language but everything must be done in a sustainable way without consuming all the resources and a cultural background is needed.

In conclusion, analyzing the development of new expansions in various parts of the world, the speed and the design typologies happening with these transformations, the contrast that is developing in the design is highlighted: the search for increasingly new and complex forms and competences in opposition to an extreme will to communicate them in a simple way.

\section{Bibliography}

Ambroise, R., P. Frapa, S. Giorgis. Paysages de Terrasses. [Landscapes of Terraces.] Edisud: Aix-en Provence, 1989.

Baricco, A. La Mappa della Metropolitana di Londra. Sulla Verità. [The London Underground Map. On Truth.] Mantova Lectures, 2017. https://www.raiplay.it/ prog rammi/mantovalectures/.

Boudon, F. "Nascita del Giardino alla Francese: Cartografia e Storia dei Castelli." [Birth of the French Garden: Cartography and History of the Castles.] In The Architecture of the Western Gardens - from the Renaissance to the Twentieth Century. Edited by M. Mosser and G. Teyssot. Milano, 1990.

Boyceau de la Baraudière, J. Traité du Jardinage Selon les Raisons de la Nature et de l'Art. [Treaty of Gardening according to the Reasons of Nature and Art.] Paris: Hachette Livre BNF, 1638.

Big Bjarke. Yes is More. Copenhagen: Ingels Group, 2011.

Burlando P. Rete di Paesaggi Costieri - Una Blueway per Porto Venere. [Network of Coastal Landscapes - A Blueway for Porto Venere.] Firenze: Alinea Editrice, 2010.

Cassell, S., S. Drake, A. Yarinsky "Manhattan - New Urban Ground.” Topos: European Landscape Magazine 73, no. 82 (2011).

D'Argenville, D. La Theorie et la Pratique $d u$ Jardinage. [Theory and Practice of Gardening.] Paris: Hachette Livre BNF, 1709.

Glancey J. What's So Great About the Eiffel Tower? 70 Questions that will Change the Way You Think about Architecture. London, Laurence King Publishing, 2017.

Rogers, E. N. Esperienze di Architettura. [Experience of Architecture.] Torino: Einaudi, 1958.

Rovelli, C. Sette Brevi Lezioni di Fisica. [Seven Short Physics Lesson.] Milano: Adelphi, 2014.

Spesso, M. Teoria dell'Architettura - Dal V secolo a.C. al Barocco. [Theory of 
Architecture - From the $5^{\text {th }}$ Century BC at the Baroque.] Padova: Libreriauniversi taria.it, 2011.

Tessari, D. La Teoria delle Ombre e del Chiaro-Scuro. [The Theory of Shadows and Light-Dark.] Torino: Camilla e Bertolero, 1880.

Yourcenar, M. Memorie di Adriano. [Memoirs of Hadrian.] Paris: Librairie Plon, 1951. 
